\title{
O Universo da Luz
}

\author{
The Universe of Light
}

\author{
Francisco Caruso ${ }^{* 1,20}$
}

\author{
${ }^{1}$ Centro Brasileiro de Pesquisas Físicas, Coordenação de Física de Altas Energias, 22290-180, Rio de Janeiro, RJ, Brasil. \\ ${ }^{2}$ Universidade do Estado do Rio de Janeiro, Instituto de Física Armando Dias Tavares, 20550-900, Rio de Janeiro, RJ, Brasil.
}

Recebido em 17 de Junho de 2020. Revisado em 20 de Julho de 2020. Aceito em 21 de Julho de 2020.

\begin{abstract}
Procura-se abordar, neste artigo, três aspectos da luz que se complementam de alguma forma: seu papel no imaginário coletivo, os esforços feitos para descrevê-la teoricamente e algumas de suas aplicações mais notáveis, tanto no desenvolvimento da Física Básica quanto Aplicada.

Palavras-chave: Luz, Física e sociedade, História da física, Divulgação científica.
\end{abstract}

This article seeks to address three aspects of light that complement each other in some way: its role in the collective imagination, the efforts made to describe it theoretically and some of its most notable applications, both in the development of Basic and Applied Physics.

Keywords: Light, Physics and society, History of physics, Science popularization.

\section{Introdução}

A luz é algo que sempre fascinou o homem. O brilho das estrelas, o Sol, o fogo. Aquilo que lhe afasta da escuridão que amedronta. Aquilo que transita entre o Céu e a Terra, merecendo, por isso, um lugar de destaque em seu imaginário (Seção 2). Além de essencial para a vida, a luz ocupa também um papel de destaque ao longo do desenvolvimento da Física e da Arte.

$\mathrm{Na}$ pintura e na fotografia, luz e sombra nos dão o contraste essencial para a percepção das formas [1], com as quais o artista representa o mundo real ou cria um mundo fictício, concreto ou abstrato, buscando transmitir alguma emoção para quem admira sua obra. Já o olhar do físico é outro. Ele quer entender o que é a luz, como ela se propaga e como vemos a partir dela. Num sentido metafórico, ele almeja dominar o fogo [2] e usá-lo a seu favor.

Tendo a ver com a visão, a luz foi objeto de investigação filosófica na Antiguidade. Se os pitagóricos haviam especulado sobre a natureza matemática da música, foi Euclides, entretanto, quem apresentou a primeira teoria matemática da visão. Ignorando a causa primeira dos fenômenos da visão que interessava alguns pensadores desse período e qualquer interesse fisiológico, preocupouse apenas com o que é observado e pode ser expresso geometricamente, seguindo o método descrito em seus Elementos. Como argumentam Caruso \& Oguri,

\begin{abstract}
sua contribuição ao ideal de geometrizar a Física, em certo sentido, foi além de Platão - que se restringiu a lançar as bases de uma Cosmologia e de uma visão da estrutura da matéria funda-
\end{abstract}

*Endereço de correspondência: francisco.caruso@gmail.com mentadas no mundo das ideias, no âmbito do que se pode chamar de uma filosofia geométrica. De fato, Euclides lançou mão de uma descrição geométrica dos fenômenos luminosos, no sentido mais atual desse termo - um sentido quase galileano -, separando a questão da propagação física da luz de outras para as quais ele não teria resposta. Ao aplicar a Geometria ao estudo da Óptica, mostrou que fenômenos reais podiam ser descritos qualitativa e quantitativamente 3.

Do ponto de vista da Física Moderna e da Física Contemporânea, estudos dos fenômenos luminosos foram parte integrante de várias descobertas experimentais importantes, da formulação de princípios fundamentais, de grandes sínteses e estiveram na base da revisão e reformulação de conceitos basilares da Física, a exemplo do que ocorreu a partir da Teoria da Relatividade e da Mecânica Quântica, como veremos ao longo do artigo (Seção 3 ). Além disso, nossa sociedade baseia-se enormemente no eletromagnetismo e dele é refém. A Humanidade tem vivenciado constantes e grandes avanços tecnológicos provenientes da compreensão teórica do que é a luz, de grande impacto social. Referimo-nos, por exemplo, às invenções do rádio, da televisão, do computador, dos satélites e de tantas outras coisas, algumas das quais serão destacadas e comentadas na Seção 4

O autor inspirou-se no famoso livro de Sir Bragg, The Universe of Light 4] e numa palestra homônima que proferiu para um público geral na Fundação Planetário, no Rio de Janeiro, para preparar esse texto com fronteiras mais amplas. 


\section{O Imaginário}

É frequente, no imaginário coletivo, que a luz esteja associada a algo bom, a algo positivo, em oposição à conotação negativa da escuridão. "Há uma luz no fim do túnel" é uma frase popular que exprime esperança. Essa é uma característica comum a vários povos, de diferentes regiões e culturas. Encontra-se presente na mitologia, na literatura e nas artes, encaixando-se em uma espécie de matriz arquetípica universal. Podemos começar citando, como exemplo dessa associação, o mito de criação expresso na bela lenda indígena brasileira (tupi) sobre Rudá, Guaraci e Jaci.

\begin{abstract}
No começo havia a escuridão. Então nasceu o sol, Guaraci. Um dia ele ficou cansado e precisou dormir. Quando fechou os olhos tudo ficou escuro. Para iluminar a escuridão enquanto dormia, ele criou a lua, Jaci. Ele criou uma lua tão bonita que imediatamente apaixonou-se por ela. Mas, quando o sol abria os olhos para admirar a lua, tudo se iluminava e ela desaparecia. Guaraci criou, então, o amor, Rudá, seu mensageiro. O amor não conhecia luz ou escuridão. Dia ou noite, Rudá podia dizer à lua o quanto o sol era apaixonado por ela. Guaraci criou também muitas estrelas, seus irmãos, para que fizessem companhia a Jaci enquanto ele dormia. Assim nasceu o céu e todas as coisas que vivem lá ${ }^{1}$
\end{abstract}

No imaginário judaico-cristão, a luz também se relaciona ao bem. De fato, assim começa o livro Gênesis:

\begin{abstract}
No princípio criou Deus o céu e a terra.
E a terra era sem forma e vazia; e havia trevas sobre a face do abismo; e o Espírito de Deus se movia sobre a face das águas.

E disse Deus: Haja luz; e houve luz.

E viu Deus que era boa a luz; e fez Deus separação entre a luz e as trevas.

E Deus chamou à luz Dia; e às trevas chamou Noite. E foi a tarde e a manhã, o dia primeiro. Gênesis 1:1-5
\end{abstract}

A seguir encontram-se duas belíssimas ilustrações da criação do céu (Figuras 1 e 2), datadas do século XV.

$\mathrm{Na}$ Grécia antiga, havia a percepção de que a luz era algo sutil e imaterial que se propagava no éter cósmico, perto dos astros (e assim pensaram os físicos até o início do século XX), transmitindo a ideia de liberdade entre o céu e a terra, nos dois sentidos. Umberto Eco chama a atenção para o fato de a luz ser única quando se considera a possibilidade de transitar entre o Céu e a Terra, que Deus separou [5]. Essa característica, além de obviamente fomentar o imaginário religioso, acaba tendo um papel importante no estudo da Óptica, no Medioevo, enquanto é ressaltada na Arte.

Talvez não por acaso, muitos religiosos dedicaram-se ao estudo da Óptica a partir da Idade Média, praticamente

\footnotetext{
${ }^{1}$ Para uma versão mais detalhada e a interpretação do mito veja http://terraderuda.org.br/2014/blog/mito-de-ruda/ acessada em 12 de junho de 2020.
}

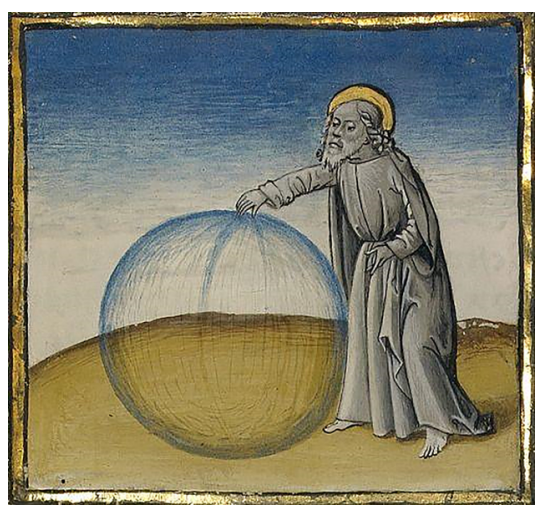

Figura 1: The Creation of the Heavens. Iluminura de autor desconhecido, de origem flamenga, circa 1475. Paul Getty Museum.

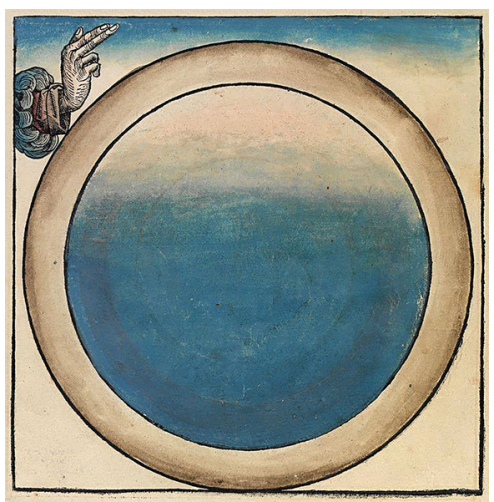

Figura 2: First day of Creation, Nuremberg Chronicle, 1493.

todos franciscanos. De fato, é possível entender o porquê, recordando a origem dessa ordem. Segundo o escritor britânico Gilbert Keith Chesterton, o aparecimento de São Francisco de Assis "marcou o momento em que os homens puderam se reconciliar não apenas com Deus, mas com a natureza e, o mais difícil de tudo, consigo mesmos" 6]. São Francisco contribui para a difusão da metáfora do Livro da Natureza 7] como caminho alternativo para o homem contemplar e chegar até Deus, além da Bíblia. Com ela, dá os primeiros passos para uma nova humanização do Mundo. Admite que o homem deva se integrar à Natureza, sem se afastar de Deus, preservandoa e admirando-a na sua plenitude. Sugere que se olhe para a Natureza como ela é. Assim, ele está antecipando em muito uma das características mais notáveis do Renascimento: um olhar desarmado, livre e crítico. Não é à toa que seu amigo, o pintor Giotto, abandona a tradição bizantina e passa a pintar o céu de azul e não mais de dourado 8, 9]. O céu como ele é.

O bispo e teólogo Robert Grosseteste, fundador da Escola Franciscana de Oxford, muito estimulou o interesse pela Óptica na Europa, no século XIII. Roger Bacon, por volta de 1240, ingressou para a Ordem Franciscana, onde, sob influência de Grosseteste, dedicou-se a estudos da perspectiva 10] e outros, introduzindo a observação da natureza e a experimentação como fundamentos do 
conhecimento natural. Na verdade ele foi além de seu tutor, antecipando ideias de Galileu Galilei que revolucionaram a Física e marcaram o que se passou a denominar Ciência Moderna, ao afirmar que o método científico depende de observação, da experimentação, da elaboração de hipóteses e da necessidade de verificação independente. No que se refere especificamente à Óptica, tanto Grosseteste quanto Bacon tiveram enorme influência de Ibn Al-Haitham - conhecido no Ocidente como Alhazen que havia escrito o importante livro De aspectibus, com uma forte descrição matemática da Óptica, explorando sua natureza geométrica [11].

Outro franciscano, que chegou a ser Arcebispo, John Peckham, escreveu um manual de Óptica que ajudou a difundi-la na Europa Central. Vitello, igualmente franciscano, influenciado por Bacon, foi autor da obra Perspectiva, que teve importante circulação na Idade Média. Muitas dessas contribuições concentraram-se nas décadas de 1260 e 1270 [12. Também o nominalismo de William de Ockham tem raízes franciscanas. Tendo feito um esforço de separar fé e razão, e defendido que a causa das coisas deve ser conhecida pela experimentação, ele é considerado o precursor do racionalismo, do cartesianismo e do empirismo moderno. Cabe lembrar aqui que os nominalistas vão tender a considerar apenas a causa eficiente de Aristóteles como a única causa necessária para explicar a Natureza. Essa escolha, como se sabe, será, mais tarde, compartilhada por Isaac Newton, constituindose no fulcro de sua Mecânica, elaborada a partir dos conceitos de massa e força 13 .

No que se refere a essa compreensão embrionária de um novo método científico, esboçada no final da Idade Média e que acaba de ser descrita muito resumidamente, é ela que, em última análise, irá libertar de vez a Ciência e, em particular a Astronomia, de todo um conjunto de atitudes cerceadoras impostas metaforicamente pela representação sistemática do céu dourado.

Por outro lado, o Sol é o astro-luz por excelência e, ao longo da história da humanidade, tem-se recorrido com frequência à luz, e ao próprio Sol, para representar o divino, como entre os povos semitas, os egípcios, os iranianos e também na platônica associação do Sol com a ideia de Bem.

Com o tempo, as Artes vão se apropriando da Luz para representar Deus. Um belo exemplo (Figura 3 ) é a iluminura feita por Giovanni di Paolo para um códex da Divina Comédia de Dante, representando o poeta e sua amada Beatriz contemplando o Pai no Paraíso.

Na Pintura, por exemplo, a luz dos neoplatônicos desce do alto e se difunde criativamente nas coisas, enquanto a claritas ${ }^{2}$ de São Tomás de Aquino sobe a partir do baixo 15 .

\footnotetext{
${ }^{2} \mathrm{Na}$ estética de São Tomás, a associação da luz com a beleza é ressaltada quando ele admite que esta é constituída de três elementos: consonantia, claritas e integritas (proporção, clareza e integridade). Em sua obra, esse termo não é usado em um único sentido, mas pode significar simplesmente a luz ou a cor física ou a luz da razão 14 .
}

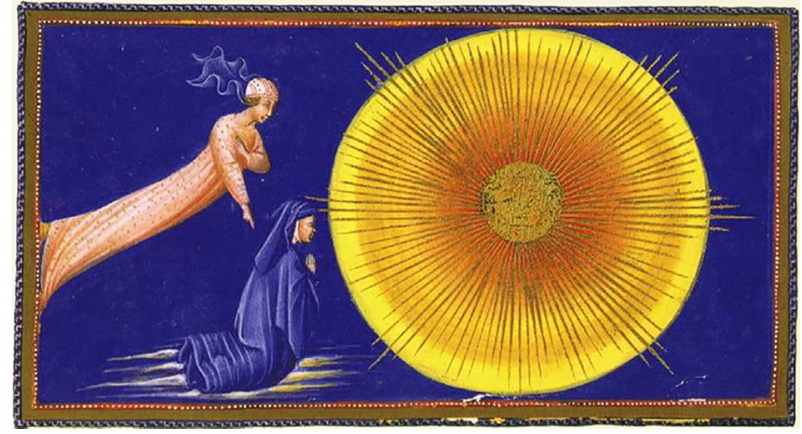

Figura 3: lluminura feita por Giovanni di Paolo para um codex da Divina Comédia, representando Dante e Beatriz ao se encontrarem com Deus. The British Library's Yates-Thompson codex, f. 179r., CANTO XXVIII.

Um típico exemplo dessa luz que desce do alto, de caráter divino, encontra-se no quadro Anunciação, de Tiziano Vecellio (Figura 4). Nele, além do aspecto emblemático da luz, enquanto elemento simbólico religioso, aqui representando o Espírito Santo, o feixe luminoso desempenha ainda a importante tarefa de guiar nosso olhar para o ponto mais significativo da peça - a própria figura da Virgem.

Entretanto, também encontra-se na pintura alguma associação da luz a algo negativo. Podemos citar, como exemplo, dois quadros que, de certa forma, estão relacionados: "Os fuzilamentos de três de Maio", de Francisco de Goya (Figura 5 - no qual, pela primeira vez, a luz é associada à repressão do estado - e "Guernica" (Figura 6), de Picasso, ambos reproduzidos a seguir ${ }^{3}$

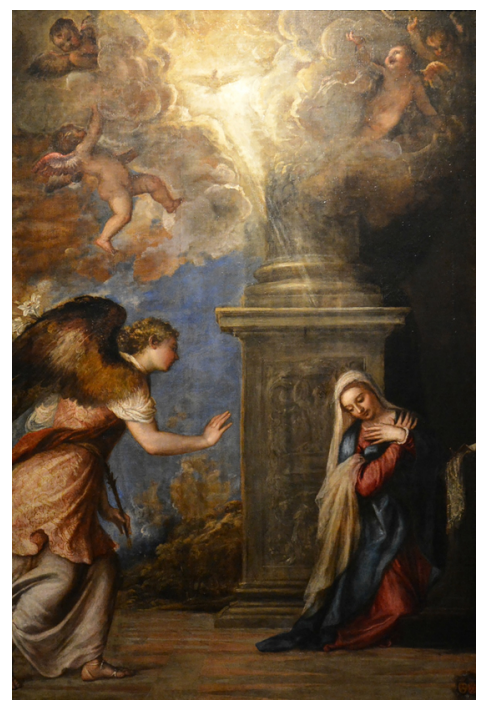

Figura 4: Annunciazzione, de Tiziano Vecellio, circa 1560-65, Museo di Capodimonte, Napoli.

\footnotetext{
${ }^{3}$ Veja o texto A leitura da obra "Guernica", de Picasso, para o estudo da história. https://mundoeducacao.uol.com br/historiageral/a-leitura-obra-guernica-picasso-paraestudo-historia.htm Acesso em 13 de junho de 2020.
} 


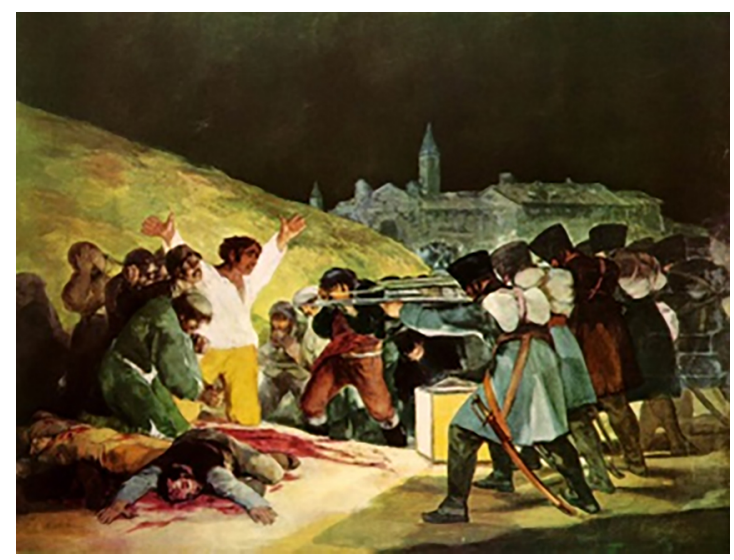

Figura 5: "Os fuzilamentos de três de Maio". Quadro pintando por Goya, em 1814, que se encontra no Museu do Prado, em Madrid.

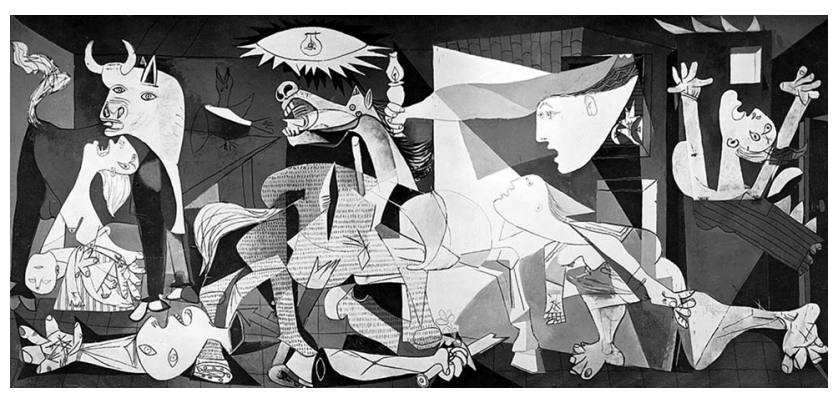

Figura 6: "Guernica", painel pintado a óleo por Pablo Picasso, em 1937. Museu Nacional Centro de Arte Reina Sofia.

Alguns historiadores da Arte acreditam que Picasso, sabedor dessa intenção de Goya retratada pelo forte foco de luz que, partindo dos executores, ilumina quem será executado, teria usado o mesmo recurso em seu "Guernica", onde o principal foco de luz está associado aos agressores, enquanto uma luz bem mais tênue, de uma lamparina, representa a escassa resistência à barbárie retratada.

\section{O Conhecimento Científico}

\subsection{De corpúsculo à onda: uma parte do caminho}

Descartes, assim como Aristóteles, não aceitava a existência do vácuo. Portanto, para ele, o mundo é permeado por um plenum, o éter. A luz era, assim, vista como uma pressão transmitida, em analogia com o que se dá na propagação do som, através de um meio perfeitamente elástico, o éter [16], meio muito leve e rarefeito, capaz de penetrar todos os corpos sem ser percebido. Em sua descrição da Natureza, era esse fluido contínuo que mediava as interações entre os corpos por meio de um sistema de vórtices. A existência ou não desse meio, desse substrato para a propagação da luz, vai ser tema de muita discussão e investigação científica até o surgimento da Teoria da Relatividade Restrita, em 1905, como veremos.

Embora Isaac Newton não tenha chegado a uma teoria definitiva a respeito da luz [17, defendia uma visão corpuscular da luz, ao contrário de Christiaan Huygens, que acreditava que a luz era um fenômeno ondulatório [18]. Essa discordância de visão acerca da luz ficou conhecida na literatura como a disputa Newton-Huygens. Embora haja evidências de que tal disputa não tenha ocorrido [19], a discordância entre os dois cientistas certamente norteou muitos outros debates.

Mas voltemos à questão da propagação da luz. Uma contribuição que gostaríamos de destacar, em especial, foi a de Pierre de Fermat, não tanto pela contribuição específica no sentido de deduzir a trajetória de propagação dos raios luminosos, mas principalmente pela natureza fundamental do princípio metafísico por ele introduzido, em 1657. Trata-se de uma tentativa de deduzir a trajetória desses raios, a partir do princípio de Fermat do tempo mínimo, com o qual ele afirma que a Natureza atua sempre pelo menor caminho. A relevância histórica dessa proposta reside no fato de ser a origem de um modo de pensar a Natureza que acabou culminando no famoso princípio da mínima ação [20].

Muitos se perguntaram sobre o que seria mínimo durante a propagação da luz e na evolução temporal de outros corpos. De forma mais geral, indagou-se sobre o que seria mínimo durante o movimento de um sistema físico. Historicamente, as respostas foram muitas e vieram de pensadores como Maupertuis [21], Euler e Lagrange [22]. A rigor, vamos compreender que a evolução de qualquer sistema físico se dá de tal maneira que sua $a c ̧ \tilde{a} o$ é um extremo (mínimo ou máximo). Segundo o matemático húngaro Cornelius Lanczos, o papel unificador dessas ideias, que tiveram origem na busca da compreensão da propagação da luz, reside no fato de que, por seu intermédio, chegou-se ao entendimento de que existe um princípio por trás do conjunto de equações que descrevem a dinâmica de um sistema físico, por mais complicado que seja, que expressa o sentido de todo esse conjunto. Dada uma quantidade fundamental - a $a c ̧ a \tilde{o}$ -, o princípio de que esta seja estacionária leva ao conjunto completo de equações diferenciais que descrevem o sistema considerado.

Por outro lado, a decomposição da luz branca feita e estudada por Newton também abriu novos caminhos. Em 1666, o jovem Newton realizou um experimento muito simples, mas importante para o estudo da luz. Assim, mais tarde, ele descreveu o que fez:

Tendo escurecido meu quarto e feito um pequeno orifício na minha cortina, para permitir a entrada de uma quantidade suficiente de luz do Sol, coloquei meu prisma próximo à entrada de luz, de forma que ela pudesse ser refratada sobre a parede oposta.

O resultado é bem conhecido: a luz solar é decomposta em várias cores, e, utilizando-se de outro prisma, Newton 
foi capaz de recompô-la. Sua interpretação para esse fenômeno foi que a luz solar seria composta de diferentes cores, cada qual tendo um índice de refração diferente. Neste caso, como a luz se refrata duas vezes no prisma, ao passar do ar para o vidro e, em seguida, do vidro de volta para o ar, cada componente (cor) sofre uma mudança de direção diferente e, portanto, há uma separação, ou uma dispersão das cores, dando origem ao espectro do arco-íris.

Em seu famoso livro Opticks, Newton declara: "meu desejo neste livro não é explicar as propriedades da luz por hipóteses, mas propor e prová-las pela razão e por experimentos".

Vão ser exatamente os experimentos de interferência e difração, que se seguiram nas primeiras décadas do século XIX, com Young, Fresnel, Foucault e Arago, a contribuir decisivamente para a aceitação da visão ondulatória de luz. A tal ponto que Edmund Whittaker corrobora essa afirmativa com as seguintes palavras [23]:

Do gênio de Young e Fresnel, a teoria ondulatória da luz foi estabelecida de modo tão forte que a partir de então a hipótese corpuscular não era mais capaz de recrutar qualquer novo adepto entre os jovens.

A grande síntese dos fenômenos luminosos, elétricos e magnéticos foi feita por James Clerk Maxwell em sua Teoria Eletromagnética [24], na qual trabalhou entre 1856 e 1864. As equações de Maxwell são expressões matemáticas das leis de Gauss para a eletricidade e o magnetismo, da lei de Ampère e da lei de Faraday-Lenz. Esse conjunto de equações leva à predição da existência de ondas eletromagnéticas, que foram, em seguida, observadas experimentalmente por Hertz. E como os físicos gostam de brincar: "Maxwell ("Deus") disse... e fez-se a luz" (Figura 7).

É o triunfo da visão ondulatória da luz. Com esse trabalho, Maxwell dá um duro golpe na proposta cartesiana-

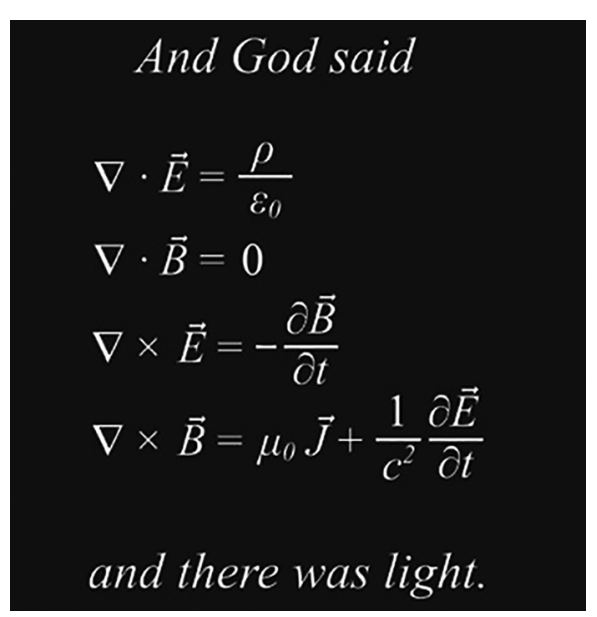

Figura 7: A criação da luz vista como consequência das Equações de Maxwell. newtoniana de mecanização da Física [27], o que já havia sido posto em xeque pela Teoria do Calor, de Fourier. A causa eficiente deixa de ser elemento central da explicação causal do Mundo e é substituída pela causa formal (a forma das equações diferenciais). O eletromagnetismo é uma Teoria Clássica de Campos, descrita por equações diferenciais parciais.

\subsection{Da espectroscopia da luz visível}

O espectro de linha mais simples, correspondente também ao átomo mais simples - o átomo de hidrogênio -, foi primeiro observado pelo sueco Anders Jöns Ångström, em 1853. Foi preciso aguardar mais de 30 anos para que um professor de Matemática e Latim, o suíço Johann Jakob Balmer, com a idade de 60 anos, matematizasse as regularidades desse espectro. Movido pela convicção de que o mundo inteiro, natureza e arte, é uma grande harmonia unificada, Balmer dedicou toda sua vida a expressar essas relações de harmonia numericamente. Como enfatizam Caruso \& Oguri 3], o modo como Balmer se referiu, na época, aos seus estudos sobre o espectro do hidrogênio pode ser considerado profético, à luz dos desenvolvimentos futuros e do papel que a compreensão do átomo de hidrogênio teve para o desenvolvimento da Física Quântica. De fato, ele afirmou o seguinte:

\begin{abstract}
Parece-me que o hidrogênio (...), mais que qualquer outra substância, está destinado a abrir novos caminhos para o conhecimento da estrutura da matéria e de suas propriedades. A esse respeito, a relação numérica entre os comprimentos de onda das primeiras quatro linhas espectrais do hidrogênio deve atrair particularmente nossa atenção.
\end{abstract}

Ele tinha toda razão.

Quase concomitantemente, entre 1855 e 1863, desenvolveu-se o que se convencionou chamar de espectroscopia, graças ao trabalho pioneiro dos alemães Robert Wilhelm Bunsen e Gustav Kirchhoff, que idealizaram, em 1860, um aparato para observação do espectro de diversos materiais 28], mostrado na Figura 8. O objetivo dessa linha de pesquisa era analisar a estrutura atômica e molecular da matéria a partir da radiação emitida pela matéria sólida ou gasosa, quando aquecida em um bico de Bunsen.

Cada elemento químico dá origem a um espectro de emissão característico, como se fosse uma espécie de "impressão digital", única para cada elemento. Para os gases monoatômicos, esses espectros, projetados em um anteparo ou visualizados por meio de um microscópio, apresentam-se, em geral, como um conjunto de linhas espaçadas e paralelas e, para os gases contendo dois ou mais átomos, como bandas contínuas.

"O termo "mecanização da Física" é utilizado aqui no sentido atribuído a ele na Ref. 25], ou seja, está relacionado a uma visão da Física científica e filosoficamente inspirada e construída nas ideias mecanicistas de Newton. A esse respeito veja também a Ref. 26. 


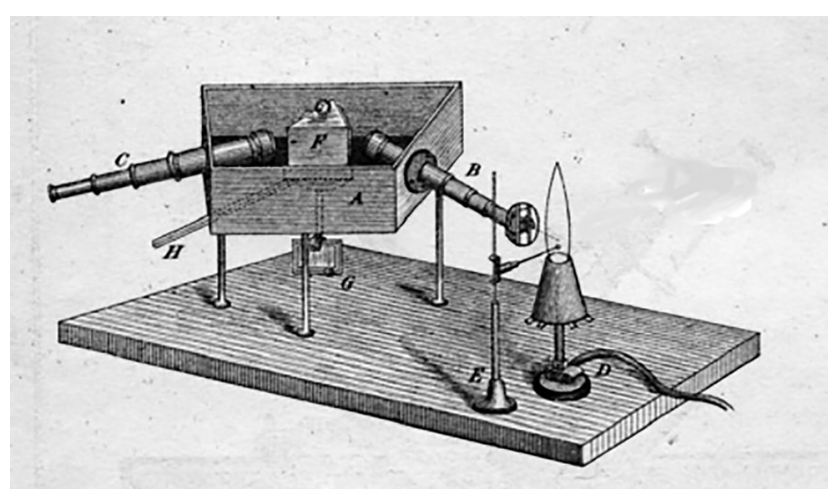

Figura 8: Ilustração do aparato idealizado e utilizado por Kirchhoff \& Bunsen, em 1860, para observação de espectros de diversos materiais.

Quando a luz branca solar, ou a luz emitida por um sólido, como o filamento de uma lâmpada incandescente, que incide sobre um gás ou vapor, passa por um prisma, observam-se algumas zonas, raias ou linhas escuras, que correspondem às frequências das radiações que foram absorvidas pelo gás. O espectro assim obtido é denominado espectro de absorção, e, em outras palavras, pode-se chamá-lo de um processo de "subtração de luz". Essa absorção seletiva de energia foi uma das primeiras evidências do caráter composto dos átomos, e de que estes estavam, de alguma forma, associados a determinadas frequências características.

A análise desses espectros permitiu a descoberta de vários novos elementos químicos, como o rubídio (Rb), o índio (In), o tálio (Ta) e o césio (Ce) $[3]$.

As primeiras investigações sistemáticas iniciaram-se em 1814 com Joseph Fraunhofer, que classificou as linhas escuras, posteriormente denominadas linhas de Fraunhofer, no meio do arco-íris de cores do espectro solar. O trabalho seminal de Bunsen \& Kirchhoff deu origem ainda a uma nova e importante área de investigação em Astrofísica, que nos levou a conhecer a composição química das estrelas a partir dos chamados espectros de absorção (Figura 9). De fato, uma grande utilidade desses espectros é a possibilidade de permitir detectar quantidades mínimas de certas substâncias em uma amostra através da análise espectral.

Por fim, a espectroscopia contribuiu para a metrologia, ao permitir que Albert Abraham Michelson, em 1892, definisse um novo padrão para o metro, que passa a ser 1553163,5 comprimentos de onda da linha vermelha do cádmio a $760 \mathrm{~mm}$ de pressão atmosférica e a $15{ }^{\circ} \mathrm{C}$, ao invés do comprimento de uma barra padrão existente no Museu de Sèvres.

\subsection{Dos Raios X}

Outra manifestação da luz que deve ser destacada aqui envolve a descoberta dos Raios X [29], por Röntgen, e seus desdobramentos, tanto no que se refere às novas

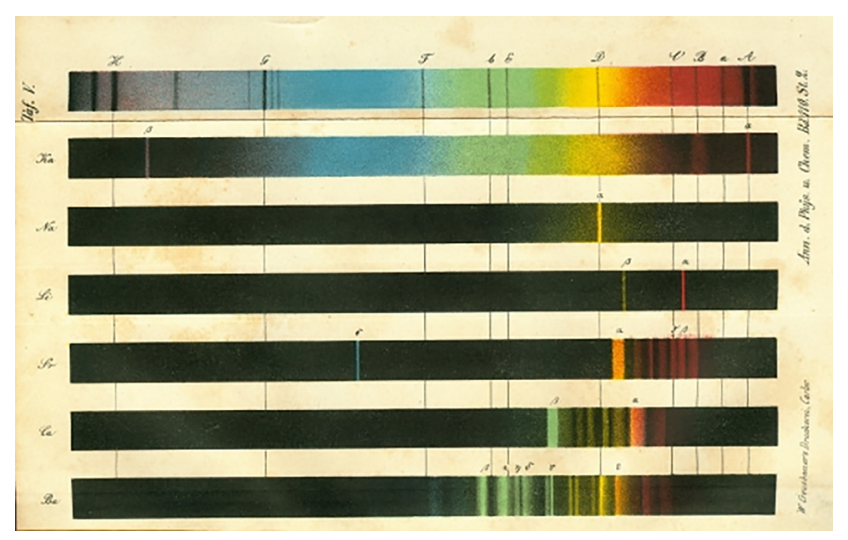

Figura 9: Prancha colorida publicada em Bunsen \& Kirchhoff, 1860. A tira superior, refere-se ao espectro solar, comparado com outros dos seguintes elementos: potássio, sódio, lítio, estrôncio, cálcio e bário. Verifica-se que as linhas escuras proeminentes no espectro solar coincidem com as linhas luminosas dos espectros abaixo, permitindo concluir sobre a composição da atmosfera solar.

descobertas em Física Básica envolvendo seu uso, quanto às aplicações nas áreas médica e tecnológica.

Em novembro de 1895, Röntgen propos-se a estudar a fluorescência de certas substâncias [30], utilizando tubos de Hittorf ou de Lenard ${ }^{5}$ Para eliminar efeitos indesejáveis, Röntgen introduziu o tubo com o qual trabalharia em uma caixa de papelão preto, de modo a bloquear raios visíveis e ultravioleta provenientes do tubo. Desse modo, apenas os raios catódicos passariam pela janela de Lenard, sendo colimados para a direção dos objetos contendo as substâncias fluorescentes. Com a sala completamente escura, Röntgen observou que um cartão coberto por uma solução de platino-cianeto de bário estava iluminado. Entretanto, os raios catódicos se propagam no ar por apenas alguns poucos centímetros, e o cartão alvejado estava localizado a cerca de dois metros. Intrigado e perplexo com a origem desconhecida do que provocou a luminescência, Röntgen deu a esses raios o nome provisório de raios $\mathrm{X} 6$

Apesar de os experimentos sobre a polarização dos raios X, de Charles Glover Barkla, em 1905, indicarem que a propagação desses raios se daria por uma perturbação transversal, a concepção ondulatória dos raios $\mathrm{X}$ só foi reforçada em 1912, quando Max von Laue propôs o experimento da difração dos raios X pela estrutura ordenada dos materiais cristalinos, realizado por seus alunos Walther Friedrich e Paul Knipping.

Do ponto de vista do desenvolvimento da Física Básica, o impacto dessa descoberta foi enorme 3. Vamos nos limitar aqui a resumir alguns deles.

Os primeiros experimentos com raios $\mathrm{X}$ estabeleceram que seus comprimentos de onda seriam da ordem de déci-

\footnotetext{
${ }_{5}^{5}$ Há controvérsias na literatura a esse respeito.

${ }^{6}$ Baseado na letra normalmente atribuída a uma incógnita de um problema a resolver, nome este que passou a ser definitivamente adotado.
} 
mos de angstrom, enquanto o espaçamento interatômico em um sólido seria da ordem de $1 \AA$ A. Desse modo, ocorreu a von Laue que, se os raios $\mathrm{X}$ fossem realmente ondas eletromagnéticas, quando excitassem os átomos espacialmente ordenados de um cristal, forçando-os a oscilar, a radiação espalhada resultaria da interferência de várias fontes coerentes, devido ao arranjo atômico regular. $\mathrm{Ou}$ seja, um cristal serviria como uma rede de difração para os raios $\mathrm{X}$.

William Henry Bragg e William Lawrence Bragg estudaram a difração de raios $\mathrm{X}$, determinando a famosa lei de Bragg. Esses trabalhos deram origem à Cristalografia. Do ponto de vista experimental, uma vez conhecida a distância entre dois planos atômicos, pode-se calcular o comprimento de onda dos raios $\mathrm{X}$ que proporciona um máximo e, vice-versa, utilizando raios $\mathrm{X}$ de comprimentos de onda conhecidos, podem-se calcular as distâncias interatômicas em um cristal. Assim é que as estruturas dos sólidos cristalinos foram precisamente determinadas, nos primórdios da Física do Estado Sólido.

Outra contribuição importante para a compreensão da estrutura atômica da matéria veio com Charles Barkla. A partir de 1904, dedicou-se a determinar experimentalmente o número de elétrons de átomos leves, valendo-se do espalhamento de raios X pela matéria. Em 1911, Barkla pode mostrar que, para átomos leves, o número de elétrons é aproximadamente a metade do número de massa do elemento.

\subsection{Da espectroscopia de raio $X$}

Henry Moseley fez um estudo sistemático dos espectros de raios X no biênio 1913-14, utilizando 38 elementos químicos diferentes como alvo 31. Moseley apresenta em seu trabalho, publicado em 1913, um método fotográfico, por meio do qual a análise dos espectros de raios $\mathrm{X}$ torna-se tão simples quanto a de qualquer outro ramo da espectroscopia. Chegou a uma relação simples entre a raiz quadrada da frequência da linha espectral observada e o número atômico do elemento, a chamada lei de Moseley.

Referindo-se ao núcleo atômico descoberto por Rutherford, em 1911, Moseley afirma o seguinte [3]:

temos aqui uma prova de que existe no átomo uma quantidade fundamental que aumenta a passos regulares quando se passa de um elemento para o próximo. Esta quantidade só pode ser a carga do núcleo central positivo, de cuja existência já temos prova definitiva.

Desta forma, com base em espectros de raios X, Moseley confirma a regra estabelecida por Antonius Johannes van den Broek, segundo a qual 3

o número serial de todo elemento na sequência ordenada pelo peso atômico crescente é igual à metade do peso atômico e, portanto, igual à carga interatômica.

Portanto, a posição de um elemento na Tabela Periódica está mais diretamente relacionada ao número atômico do que ao peso atômico. Esse fato mostra, claramente, que as propriedades químicas são diretamente relacionadas à carga nuclear e não determinadas pela magnitude do peso atômico, como acreditava Mendeleiev. Isso levou Rutherford, em 1917, a comparar a contribuição científica de Moseley à de Mendeleiev, talvez não sem razão. De fato, a Tabela Periódica que temos hoje deve muito a Moseley.

\subsection{Do espalhamento de raio $\mathrm{X}$}

Por outro lado, foi também a partir de experimentos com raios X que Arthur Holly Compton, em 1922, obteve evidências de que a radiação eletromagnética (a luz), na interação com a matéria, se comportava, em alguns casos, como se fosse constituída de feixes de partículas - os fótons 32,33 - que obedeciam às leis de conservação relativísticas de momentum e de energia. Esse foi outro momento importante, envolvendo raios X 7 para a compreensão de um processo físico elementar, relacionado ao problema da dualidade onda-partícula na Velha Mecânica Quântica.

\subsection{Do espectro de corpo negro ao quantum: a outra parte do caminho}

"Nunca na história da Física houve uma interpolação matemática tão imperceptível com tão amplas consequências físicas e filosóficas", disse uma vez o historiador da ciência Max Jammer, a propósito da contribuição de Max Planck à Física do Corpo Negro 34.

O problema da regularidade do espectro emitido por um corpo negro vinha sendo estudado desde a metade do século XIX e estava relacionado ao problema de altosfornos da siderurgia alemã e, portanto, não era um tema central de Física Básica naquela época. Entretanto, seu impacto sobre ela foi fabuloso.

Avanços experimentais, devidos principalmente a Ferdinand Kurlbaum e Heinrich Rubens, do PhysicalishTechnische Reichsanstalt, de Berlim, fizeram Planck perceber que o espectro de corpo negro tinha dois comportamentos assintóticos diferentes [3]: um (o limite de baixas frequências) expresso corretamente pela fórmula de Lord Rayleigh e o outro (altas frequências), pela fórmula de Wien. Esse fato o levou, a partir de argumentos termodinâmicos, a propor, com sucesso, uma fórmula de interpolação para a densidade espectral de energia irradiada por um corpo negro. Planck se deu conta de que a entropia dos osciladores que compunham o corpo negro poderia ser determinada por argumentos probabilísticos, ou melhor, a partir da Mecânica Estatística desenvolvida por Boltzmann. Assim, conclui que a frequência de cada componente monocromática da radiação emitida seria igual à frequência natural de vibração de osciladores elementares que compunham o corpo negro, cujas

\footnotetext{
${ }^{7}$ Algumas das aplicações práticas dos raios X serão apresentadas na Seção 4.
} 
energias $(E)$ só poderiam assumir valores discretos, múltiplos inteiros de um quantum de energia proporcional a essa frequência $(\nu)$; a famosa equação $E=n h \nu$. A constante $h$, denominada posteriormente de constante de Planck, é a constante fundamental da nova teoria física que emergiu, ao término do primeiro quarto do século XX, para descrever a evolução ou a dinâmica das partículas microscópicas, a Mecânica Quântica.

Tanto Louis de Broglie quanto Erwin Schrödinger deram contribuições à compreensão da Física Quântica baseados nos estudos de Hamilton, de 1835, nos quais estabelecem-se analogias formais entre a Óptica e a Mecânica Clássica. Nas palavras do próprio de Broglie [3],

[Schrödinger] aprofundando a analogia assinalada (...) por Hamilton, entre a Óptica Geométrica e a Mecânica Analítica, conseguiu escrever a equação geral de propagação, válida na aproximação não relativística, para uma onda associada a um corpúsculo em um dado campo (...).

No início da década de 1920, Schrödinger havia trabalhado na teoria das cores e em outros temas ligados à luz 35. Cabe enfatizar que toda essa experiência trabalhando em Óptica vai ser essencial para o modo pelo qual o físico austríaco chegou à sua equação fundamental, em analogia à equação eikonal da propagação dos raios luminosos 3 .

\subsection{Da Teoria da Relatividade}

As teorias da Relatividade Restrita, publicada em 1905 no artigo intitulado "Sobre a Eletrodinâmica dos corpos em movimento", e da Relatividade Geral, em 1915, mudaram para sempre a maneira como entendemos o Universo. Espaço e tempo deixam de ser independentes e Einstein cria um novo conceito revolucionário na Física, o de espaço-tempo. O espaço, no qual medimos distâncias, e o tempo, que quantificamos com os relógios, não são nem absolutos nem independentes: eles estão unidos e formam um universo a quatro-dimensões e é nesse novo espaço-tempo que os eventos ocorrem. As medidas de espaço e de tempo dependem essencialmente das condições de movimento dos observadores. A ideia de que a Física é a mesma para observadores que se movem relativamente uns aos outros em movimento uniforme é, nesse trabalho, consequência do postulado da invariância da velocidade da luz no vácuo $(c)$, que não depende do estado de movimento de sua fonte. A constante $c$ é um parâmetro de escala ${ }^{8}$ da teoria e uma constante universal da Física. Einstein deu, assim, ao princípio da relatividade um alcance mais universal, estendendo-o aos fenômenos eletromagnéticos e a qualquer movimento. $\mathrm{O}$ Eletromagnetismo de Maxwell passa ser o paradigma de

\footnotetext{
${ }^{8} \mathrm{~A}$ velocidade da luz, que relaciona as escalas de espaço e tempo, segundo a Teoria da Relatividade Restrita de Einstein, tem um valor fixo no vácuo, independente do estado de movimento da fonte; portanto, introduz uma relação de escala entre essas duas grandezas.
}

teoria física, guiando, inclusive, a construção de novas teorias.

Com a Teoria da Relatividade Geral, Einstein estende o princípio da Relatividade Restrita, como ficou conhecida a Relatividade de 1905, aos movimentos acelerados, do que resulta uma nova teoria da Gravitação e a base teórica de uma Cosmologia Científica.

Do ponto de vista epistemológico, Einstein foi, talvez, um dos pensadores que reviu o maior número de conceitos basilares da Física, tais como: os conceitos absolutos de espaço e de tempo, além dos de massa, de energia e o próprio conceito de simultaneidade. Além disso, conclui, no artigo de 1905, que o éter é supérfluo, ou seja, que a luz pode se propagar no vácuo.

\subsection{Do modelo de Bohr e da dualidade onda-partícula}

Niels Bohr foi quem primeiro percebeu que a estabilidade da matéria dependeria da introdução da constante de Planck na descrição do átomo, ou seja, era preciso formular um modelo quântico para o átomo, pois o modelo de Rutherford era mecanicamente instável. Concentrado na emissão de luz pelo átomo de hidrogênio, sua atenção se volta para o processo elementar envolvido. Segundo Edmund Whittaker 23], essas são as hipóteses de Bohr:

- os átomos produzem as linhas espectrais uma de cada vez;

- o átomo de Rutherford oferece uma base satisfatória para os cálculos exatos dos comprimentos de onda das linhas espectrais;

- a produção dos espectros atômicos é um fenômeno quântico;

- um simples elétron é o agente desse processo;

- dois estados distintos do átomo estão envolvidos na produção de uma linha espectral;

- a relação $E=h \nu$, correlacionando a energia e a frequência da radiação, é válida tanto para a emissão como para a absorção.

Dessa forma, ele contribui para a generalização da crise da Física Clássica contida na expressão dualidade onda-partícula. Louis de Broglie vai associar uma onda ao elétron cujo comprimento de onda será $\lambda=h / p$. Portanto, se antes só a luz poderia, de acordo com o tipo de experimento, apresentar um caráter dual, agora também o elétron deverá se comportar ora como onda, ora como corpúsculo, o que foi efetivamente observado 36 . 37. Além disso, Kapitza \& Dirac fizeram uma previsão interessantíssima [38, verificada bem mais tarde [39]. Esses dois passos, o de Niels Bohr e o de Louis de Broglie, são fundamentais para a futura unificação das descrições quânticas da matéria e da luz. De fato, foi com base nos estudos que fez da teoria de L. de Broglie que Schrödinger chegou à sua equação.

Por outro lado, os postulados de Bohr pressupõem uma renuncia a todas as tentativas de visualizar ou de explicar classicamente o comportamento do elétron agente 
do processo durante uma transição do átomo entre um estado estacionário e outro. Segundo o testemunho de Dirac 40,

\begin{abstract}
Heisenberg disse que as órbitas de Bohr não são muito importantes. As coisas que são observadas, ou que estão estreitamente conectadas com as quantidades observadas, estão todas associadas com duas órbitas de Bohr e não apenas com uma órbita de Bohr: duas e não uma $9^{9}$
\end{abstract}

Vemos aqui a gênese da ideia de que a Física Quântica deve tratar apenas dos observáveis, segundo o ponto de vista de Heisenberg, que não nos parece ser estranho ao pensamento que norteou Bohr, doze anos antes, a propor o primeiro modelo quântico do átomo. O observável o espectro de Balmer, no caso - depende da emissão de fótons pela transição do elétron entre duas órbitas. Apenas isso é observável; a órbita em si, não.

Para concluir essa Seção, um comentário sobre a coerência das visões corpuscular e ondulatória no caso da luz. Se considerarmos a primeira visão, como o fóton não tem massa, a relação entre sua energia $(E)$ e seu momentum $(p)$, dada pela fórmula de Einstein, se escreve

$$
E=p c
$$

Agora, considerando a luz como onda, seu comprimento de onda $(\lambda)$ e sua frequência $(\nu)$ satisfazem a relação clássica

$$
\lambda \nu=c
$$

na qual $c$ é a velocidade de propagação da luz. Por outro lado, a energia do fóton, de acordo com a Física Quântica, é dada pela equação de Planck

$$
E=h \nu
$$

enquanto seu momentum, de acordo com de Broglie, vale

$$
p=\frac{h}{\lambda}
$$

As duas últimas equações "misturam" o caráter de partícula (caracterizado pelas grandezas $E$ e $p$ ) com o ondulatório (caracterizado por $\nu$ e $\lambda$ ). A dualidade ondapartícula só se manifesta, portanto, em sistemas para os quais a ação envolvida é da ordem de $\hbar$. Note que, estritamente no caso de partículas de massa de repouso nula, como é o caso do fóton, esse conjunto de quatro equações é perfeitamente coerente. Ou seja, eliminando qualquer uma delas, a equação eliminada é reobtida a partir das outras três. No caso do elétron, por exemplo, isso não é mais verdade. O mesmo ocorre no caso não relativístico no qual a partícula livre tem uma energia $E=p^{2} /(2 m)$, que não é mais linear em $p$.

${ }^{9} \mathrm{O}$ grifo é nosso.

\subsection{Da contribuição de Dirac}

Uma das primeiras tentativas de descrever a interação da luz com a matéria data da primeira metade da década de 1890 e deve-se a Hendrik Antoon Lorentz 41, 42, que combina o Eletromagnetismo e a Mecânica Clássica com um modelo atomístico da matéria, o chamado modelo de Drude-Lorentz 43].

Apesar de lograr algum sucesso, como a explicação da dispersão da luz, a Eletrodinâmica Clássica de Lorentz encontra sérias dificuldades no século XX. A existência de novos fenômenos luminosos, como o efeito fotoelétrico e outros fenômenos envolvendo os processos de emissão e absorção da luz que não admitiam uma explicação ondulatória, tampouco eram compatíveis com a concepção corpuscular calcada na Mecânica de Newton e na Eletrodinâmica de Lorentz, levou Einstein a uma nova concepção corpuscular da luz, com a qual ele consegue explicar o efeito fotoelétrico, em 1905, utilizando a ideia do quantum de Planck, postulando que a energia de um feixe luminoso, em vez de estar distribuída continuamente através do espaço nos campos elétrico e magnético, estaria distribuída discretamente por pequenos pacotes de energia ou fótons (os quanta de luz).

A necessidade de se ter uma teoria eficaz e coerente para a interação da luz com a matéria persistia. Dirac buscou construir uma teoria quântica e relativística, admitindo que a equação da Mecânica Quântica é a equação de Schrödinger, na forma compacta em termos do operador hamiltoniano:

$$
H \psi=i \hbar \frac{\partial \psi}{\partial t}
$$

Dessa forma, as derivadas espaciais deveriam ser também de primeira ordem como a derivada temporal, assegurando a invariância relativística. Assim, ele chega a uma equação matricial, conhecida como equação de Dirac, a partir da qual ele prevê a existência do anti-elétron (pósitron) e reformula o conceito de vácuo, como é bem sabido 44.

Historicamente, a descoberta do elétron havia contribuído para a desconstrução do átomo químico, levando a uma nova compreensão das ligações químicas em termos físicos; ou seja, abriu caminho para o entendimento de que elas teriam uma origem eletromagnética. Do ponto de vista prático, permitiu o desenvolvimento dos primórdios da Eletrônica; do ponto de vista filosófico, põe um ponto final na ideia de que os átomos seriam realmente partículas indivisíveis, como o termo grego continua sugerindo.

Por outro lado, a previsão da existência do pósitron, feita por Dirac, e sua quase que imediata descoberta por Anderson tiveram um impacto enorme na Física Teórica e Experimental do século XX. De fato, podemos afirmar que a existência do pósitron: (i) revolucionou o conceito de vácuo, que ainda permanecia praticamente intacto desde o atomismo filosófico grego, sendo, portanto, uma das maiores contribuições para a compreensão do que é a 
matéria, a partir do momento que a ela Dirac contrapõe o conceito de anti-matéria como algo intrinsecamente relacionado ao vácuo; (ii) consolidou uma nova concepção acerca da natureza quântico-relativística do spin; (iii) provocou uma revisão do próprio conceito de partícula elementar; (iv) permitiu a consolidação de uma Teoria Quântica de Campos, a QED, capaz de descrever muito bem as interações da luz com a matéria; (v) contribuiu para que o estudo das simetrias do espaço-tempo e das ditas simetrias "internas" passasse a desempenhar um papel central no desenvolvimento da Física Contemporânea; (vi) abriu um novo capítulo para a Eletrônica de Semicondutores; (vii) ampliou muito os horizontes na busca experimental de novos constituintes últimos da matéria 45]. Isto tudo nos dá a justa dimensão da relevância dos trabalhos de Dirac para uma nova compreensão da Natureza.

Essa importante contribuição de Dirac está na base do desenvolvimento da Eletrodinâmica Quântica (QED) e da Teoria Quântica de Campos, em geral. É no âmbito do formalismo geral dessa teoria - capaz de descrever os novos processos de criação e aniquilação de partículas que se define o vácuo e se descreve a dinâmica das interações entre partículas elementares por meio de campos, o que, por sua vez, determina a revisão do próprio conceito de partícula elementar. Embora "estranha" [6, 47], a QED é a teoria física mais bem sucedida. Faz parte dessa estranheza o fato de que passa a ser possível a luz interagir com ela mesma (Figura 10 .

\section{Aplicações}

De todas as descobertas científicas, talvez o raio $\mathrm{X}$ de Röntgen tenha sido aquela de mais rápida aplicação prática, na área médica. Permitiu o impensável até então: ver dentro do corpo humano sem abri-lo cirurgicamente. Apesar de absorvidos e bloqueados por finas folhas metálicas, os raios X possuíam um poder de penetração em materiais como a madeira e o papel muito maior que qualquer onda eletromagnética conhecida. Essa propriedade foi que permitiu a radiografia dos ossos do corpo humano, uma vez que, enquanto os tecidos e os nervos são facilmente atravessados pelos raios X, os ossos, por

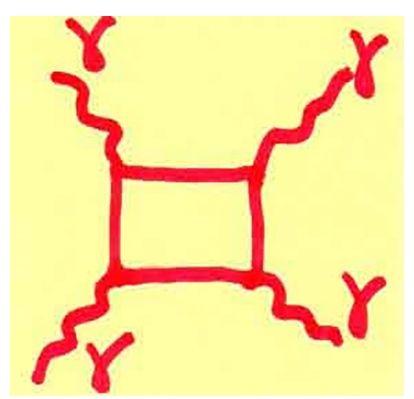

Figura 10: Diagrama de Feynman para o espalhamento $\gamma \gamma \rightarrow$ $\gamma \gamma$.

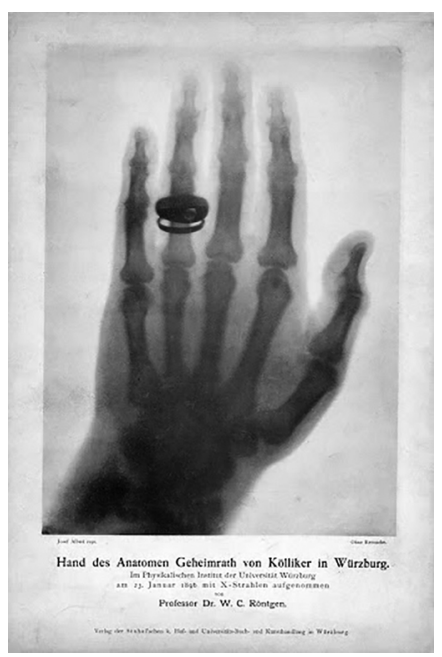

Figura 11: Radiografia tirada pelo próprio Röntgen da mão do professor de anatomia, A. Köllicker, em 1896.

conterem cálcio (Ca), são suficientemente opacos para produzir sombras em uma placa fotográfica. Assim, praticamente dois meses depois da sua descoberta, foi tirada a primeira radiografia (Figura 11), da qual já se podia antever o grande impacto que teria sobre a Medicina.

Outra aplicação prática foi idealizada por Marie Curie e batizada de "Petit Curie" (Figura 12). Eram veículos adaptados de modo a permitir que radiografias de soldados feridos no front da I Guerra Mundial fossem feitas no local, ganhando, assim, muito tempo e salvando muitas vidas. Durante a Guerra, cerca de 1 milhão de radiografias foram feitas.

Mais recentemente, técnicas de raios $\mathrm{X}$ permitiram ler papiros do século I queimados pela histórica erupção do vulcão Vesúvio (Figura 13 - conhecidos como Papiros (da cidade) de Herculano, arrasada junto com Pompeia [48]. Cientistas do Conselho Nacional de Pesquisa da Itália (CNR) revelaram, pela primeira vez, os segredos de um dos vários papiros enrolados que, em

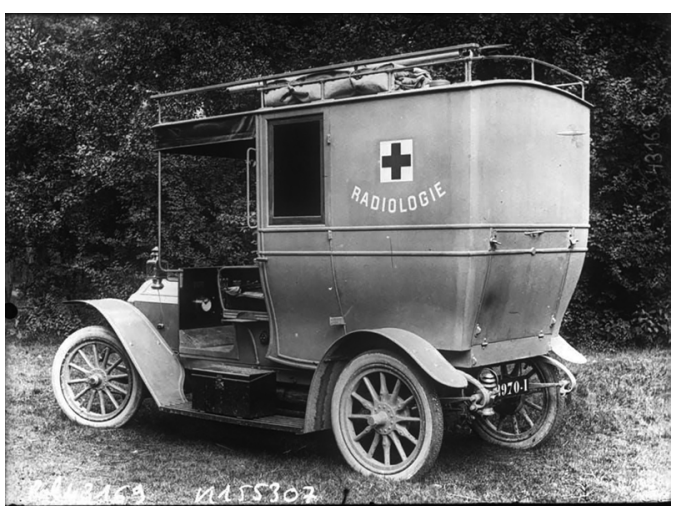

Figura 12: "Petit Curie", apelido dado ao "carro radiologista", inventado pela Mme. Curie para realizar radiografias na frente de batalha na I Guerra Mundial. Biblioteca Nacional da França, departamento de impressos e fotografias. 


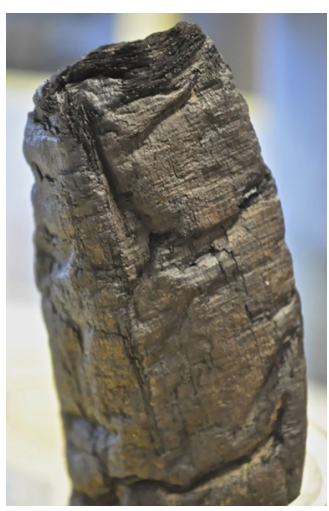

Figura 13: Foto de um dos papiros de Herculano decifrados por técnicas de raio $X$.

1752, apareceram em uma antiga biblioteca devastada pela lava. Uma imagem tridimensional do interior dos rolos, obtida graças a uma técnica utilizada habitualmente em procedimentos médicos, permitiu distinguir o relevo da tinta que se conserva sobre o material queimado.

Por último, vale citar que os raios $\mathrm{X}$ podem ser usados para monitorar rachaduras em tubos industriais ou de transporte de petróleo.

Outro exemplo importante de aplicação médica da luz é a Tomografia por Emissão de Pósitrons (PET, da sigla em inglês). A PET baseia-se basicamente no fato de que a matéria aniquila-se com a antimatéria. Elétrons $\left(e^{-}\right)$ presentes no corpo do paciente irão se aniquilar com pósitrons $\left(e^{+}\right)$- provenientes do decaimento beta do próton: $p \rightarrow n+e^{+}+\bar{\nu}$, emitidos por um radionuclídeo que seja emissor de pósitrons, previamente injetado na corrente sanguínea do paciente.

Um radionuclídeo, ligado a um composto farmacológico para ser utilizado como traçador, é denominado radiofármaco. A escolha do traçador é ditada pelas afinidades

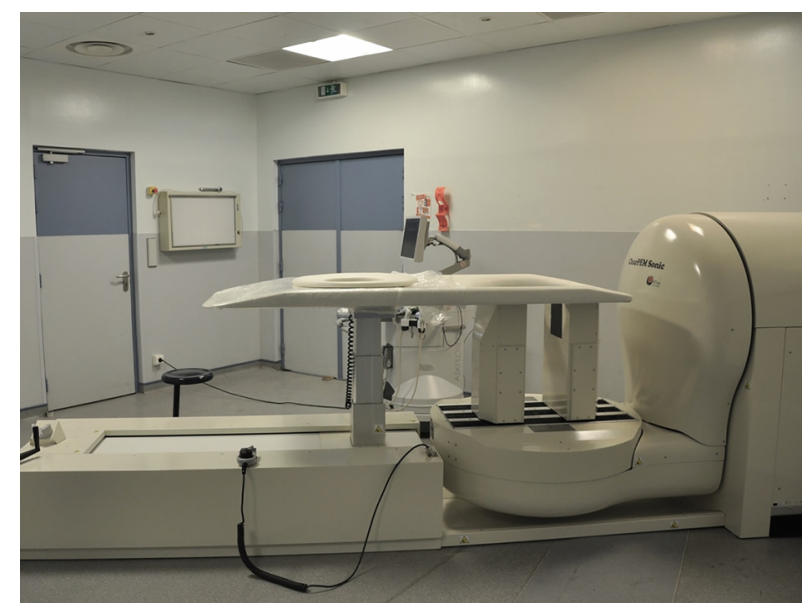

Figura 14: Aparelho de Tomografia por Emissão de Pósitrons (PET) instalado no ICNAS, Faculdade de Medicina, Coimbra, e no Hospital Universitário do Mediterrâneo, França. Foto gentilmente cedida por Alberto Santoro. químicas que possui com determinados órgãos do corpo humano. É ele que, em um hospital, uma vez injetado no paciente que será submetido a exame com um equipamento de detecção (Figura 14), transporta a substância radioativa para o órgão ou tecido a ser diagnosticado ou tratado. Um dos mais utilizados é o ${ }^{18} \mathrm{~F}$ fluordeoxiglicose (FDG) 49].

Os tecidos do corpo que são afetados por determinadas doenças, como o câncer, podem absorver mais (ou menos) de um radiofármaco do que o tecido normal e são identificados por padrões de atividade metabólica das lesões.

Detectores especiais (Figura 14 coletam o padrão de fótons emitidos pelo corpo, criando imagens que mostram o percurso do radiofármaco e o local onde se acumula. De fato, para que a emissão do pósitron seja detectada e transformada em imagem, os dois fótons (raios $\gamma$ ) resultantes da aniquilação $e^{+} e^{-}$devem ser detectados simultaneamente. Os dados são transformados em coordenadas geométricas para cada evento de aniquilação e são armazenados na memória do computador. Naturalmente, são necessários diversos pares de detectores adjacentes envolvendo todo o corpo do paciente. Isto permite a aquisição simultânea de dados, que são usados para reconstruir imagens em planos diversos 50 .

Esse tipo de exame pode evidenciar problemas em órgãos internos melhor do que as imagens obtidas com raios $\mathrm{X}$ convencionais. No caso do exame preventivo de seio não é necessário comprimi-lo tanto como em exames tradicionais, evitando grande desconforto. Sua definição muito grande evitaria muitas cirurgias inúteis mas, sobretudo, permitira a detecção do cancer de mama bem no início, quando a possibilidade de cura é bastante grande.

Como último exemplo, gostaríamos de mencionar a radiação cósmica de fundo em micro-ondas, pois envolve um tipo especial de luz relacionada com os primórdios do Universo. Essa radiação de fundo, de origem eletromagnética, preenche todo o universo. Seu espectro é o de um corpo negro a uma temperatura de 2,725 kelvin. Duas predições podem ser apontadas como entre os maiores sucessos da teoria do Big Bang: a forma de seu espectro de corpo negro praticamente ideal e as anisotropias na radiação cósmica de fundo em micro-ondas. Essas anisotropias através de todo o céu foram medidas pela sonda Wilkinson Microwave Anisotropy Probe (WMAP) e seu mapa clássico é mostrado na Figura 15

\section{Comentários finais}

Sabemos que a luz é vital para nossa vida, mas, mais do que isso, ela pode ter sido essencial para a criação da vida. De fato, há uma teoria que afirma que a origem da vida em um estado primitivo da Terra teria ocorrido quando ela estava envolta em uma atmosfera muito diferente da atual, composta de metano, água, amoníaco 


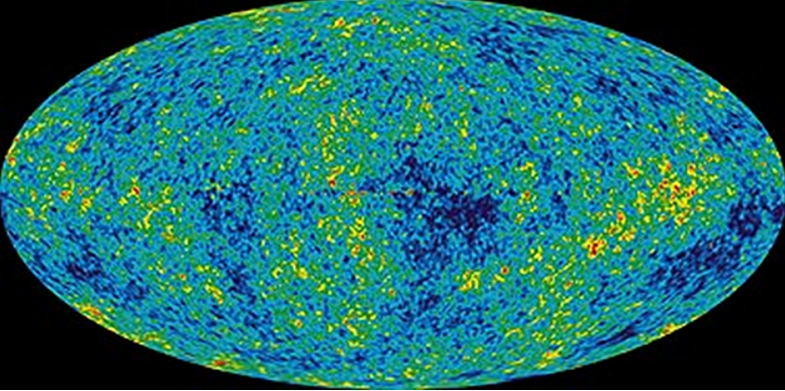

Figura 15: A ilustração mostra a radiação de fundo de microondas, conforme mapeado pela sonda WMAP (Wilkinson Microwave Anisotropy Probe). É medido chegando quase completamente uniformemente de todas as direções do espaço, com uma temperatura de aproximadamente $-270{ }^{\circ} \mathrm{C}$. As cores diferentes mostram os desvios mínimos dessa temperatura.

e hidrogênio ${ }^{10}$ Indícios a favor dessa hipótese foram encontrados no clássico experimento de 1953 feito pelos químicos Harald C. Urey e Stanley Miller 53 54]. Eles demonstraram ser possível, por meio de descargas elétricas (que simulariam relâmpagos na atmosfera primordial), transformar uma mistura com os componentes químicos inorgânicos citados em um grande número de compostos orgânicos, dentre os quais alguns aminoácidos essenciais à vida.

Vimos também o quanto a luz foi importante no desenvolvimento da Física: às vezes com protagonismo, em outras não tanto. Em particular, as duas Revoluções Científicas do século XX - A Relatividade e a Mecânica Quântica - foram frutos de uma compreensão totalmente nova do que é a luz, da qual resultou um corte epistemológico no sentido bachelardiano do termo. Os estudos da Física acabaram despertando interesses filosóficos como, por exemplo, com relação à questão do Ser. Antes da QED, não se sabia exatamente o que era a luz, fato esse que os físicos preferiram "esconder" na expressão dualidade onda-partícula. No fundo, o que ela realmente quer dizer é que ainda faltava uma teoria para a luz. Sabia-se apenas que, em certos experimentos, ela se comportava como onda, em outros, como composta de partículas.

Revimos também seu papel decisivo em muitos experimentos cruciais para a História da Física e uma pequena amostra de seu valor para o desenvolvimento tecnológico e em aplicações médicas. O futuro da tecnologia pode estar relacionado ao desenvolvimento da Óptica Quântica. No que se refere à Teoria da Informação Quântica, há avanços na chamada codificação super-densa e na criptografia quântica 55 e o sonho de vermos viabilizado um computador quântico [56], que trará uma revolução cujo impacto é hoje muito difícil de avaliar.

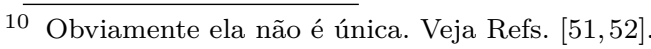

\section{Referências}

[1] M. Baxandall, Luz \& Sombra (Editora da Universidade de São Paulo, São Paulo, 1995).

[2] W. Roebroeks e P. Villa, Proceedings of the National Academy of Sciences of the United States of America 108, 5209 (2011).

[3] F. Caruso e V. Oguri, Física Moderna: Origens Clássicas e Fundamentos Quânticos (LTC, Rio de Janeiro, 2016).

[4] W.H. Bragg, The Universe of light (The Macmillan Co., London, 1933).

[5] U. Eco, Arte e Bellezza nell'Estetica Medievale (Bompiani, Milano, 1987), p. 59.

[6] G.K. Chesterton, São Francisco de Assis (Editora Madalena, São Paulo, 2016), p. 137.

[7] F. Caruso e R. Moreira Xavier, O livro, o espaço e a natureza: Ensaio sobre as leituras do mundo, as mutações da cultura e do sujeito (Livraria da Física, São Paulo, 2017).

[8] F. Caruso, Norte Ciência 3, 62 (2012).

[9] F. Caruso, Leituras da História 34, 60 (2010).

[10] D.C. Lindberg, Roger Bacon and the Origin of Perpectiva in the Middle Ages: A critical Edition and English translation of Bacon's Perspectiva with introduction and notes (Claredon Press, Oxford, 1996).

[11] D.C. Lindberg, in Encyclopedia of the History of Arabic Science, editado por Roshdi Rashed (Routledge, Reino Unido, 1996), p. 716.

[12] E. Grant, A Source Book in Medieval Science (Harvard University Press, Cambridge, Massachusetts, 1974).

[13] A.J. Snow, Matter and Gravity in Newton's Physical Philosophy (Oxford University Press, Oxford, 1926).

[14] U. Eco, The Aesthetics of Thomas Aquinas (Harvard University Press, Cambridge, Massachusetts, 1988), p. 104.

[15] U. Eco, Arte e Bellezza nell'Estetica Medievale (Bompiani, Milano, 1987).

[16] J. Navarro (Ed.), Ether and Modernity: The Recalcitrance of an Epistemic Object in the Early Twentieth Century (Oxford University Press, Oxford, 2018).

[17] R.A. Martins e C.C. Silva, Revista Brasileira de Ensino de Física 37, 4202-1 (2015).

[18] C. Huygens, Cadernos de História e Filosofia da Ciência Serie 1 Suplemento 4, 5 (1986).

[19] B.A. Moura, Caderno Brasileiro de Ensino de Física 33, 111 (2016).

[20] C. Lanczos, The Variational Principles of Mechanics (Dover, New York, 4th ed., 1986).

[21] A.P.B. Silva e R.A. Martins, Revista Brasileira de Ensino de Física 29, 625 (2007).

[22] W. Yourgrau e S. Mandelstam, Variational Principles in Dynamics and Quantum Theory (Dover, New York, 1979).

[23] E. Whittaker, A History of the Theories of Aether and Electricity(Dover Publications, Mineola, 1987)

[24] A. Beléndez, Revista Brasileira de Ensino de Física 30, 2601-1 (2008).

[25] E.J. Dijksterhuis, The Mechanization of the World Picture: Phytagoras to Newton. (Princeton University Press, Princeton, 1986).

[26] B.J.T. Dobbs e M.C. Jacob, Newton and the Culture of Newtonianism (Humanity Books, New York, 1998).

[27] V.A. Bezerra, Scientia Studia 4, 177 (2006). 
[28] G. Kirchhoff e R. Bunsen, Annalen der Physik und Chemie 110, 161 (1860)

[29] C.A. Santos, Ciência Hoje 26, (1995).

[30] W.C. Röntgen, Sitzunsgberichte Physik-med. Gesselschaften Würzburg 137 (1895).

[31] O.A.P. Tavares, Ciência e Sociedade 1, 1 (2013).

[32] F. Caruso e V. Oguri, Ciência e Sociedade 4, 1 (2016). .

[33] C.A. dos Santos, in A luz e algumas de suas tecnologias: Um estudo da física (Editora UEPG, Ponta Grossa, 2017).

[34] M. Jammer, The Conceptual Development of Quantum Mechanics (MacGraw-Hill, New York, 1966), p. 18.

[35] J.M.F. Bassalo e F. Caruso, Schrödinger (Livraria da Física, São Paulo, 2014).

[36] C. Davisson e L.H. Germer, Physical Review 30, 705 (1927).

[37] C. Davisson e L.H. Germer, Nature 119, 558 (1927).

[38] P.L. Kapitza e P.A.M. Dirac, Proceedings of the Cambridge Philosophical Society 29, 297 (1933).

[39] D.L. Freimund, K. Aatooni and H. Batelaan, Nature 413, 142 (2001).

[40] P.A.M. Dirac, Directions in Physics (John Wiley, New York, 1978).

[41] H.A. Lorentz, Archives néerlandaises des Sciences exactes et naturelles 25, 363 (1892).

[42] H.A. Lorentz, Versuch einer Theorie der electrischen und optischen Erscheinungen in bewegten Körpern (E.J. Brill, Leiden, 1895).

[43] R. McCormmach, Isis 61, 459 (1970).

[44] F. Caruso, in Partículas Elementares: 100 Anos de Descobertas, editado por F. Caruso, V. Oguri e A. Santoro (Editora da Universidade Federal do Amazonas, Manaus, 2005), p. 133.

[45] J.M.F. Bassalo e F. Caruso, Dirac (Livraria da Física, São Paulo, 2013).

[46] R. Feynman, QED: A estranha teoria da luz e da matéria (Gradiva, Lisboa, 1988).

[47] F. Caruso e V. Oguri, Ciência e Sociedade 4, 11 (2016).

[48] V. Mocella, E. Brun, C. Ferrero e D. Delattre, Nature Communications 6, 5895 (2015).

[49] C.C. Robilotta, Revista Panamericana de Salud Pública 20, 134 (2006).

[50] A.C.B. Machado, V. Pleitz e M.C. Tijero, Revista Brasileira de Ensino de Física 28, 407 (2006).

[51] A.I. Oparin, Origin of Life (Dover, New York, 1953).

[52] A.G. Cairns-Smith, Seven Clues to the Origin of Life: A Scientific Detective Story (Cambridge University Press, Cambridge, 1990).

[53] H.C. Urey e S. Miller, Science 130, 245 (1959).

[54] H.C. Urey e S. Miller, Science 30, 1622 (1959).

[55] N. Gisin; G. Ribordy; W. Tittel e H. Zbinden, Review of Modern Physics 74, 145 (2002).

[56] M.A. Nielsen e I. Chung, Quantum Computation and Quantum Information (Cambridge University Press, New York, 2000). 